\title{
Youubi: Ambiente de Aprendizagem Ubíqua
}

\author{
Bruno de Sousa Monteiro ${ }^{1}$, Everton Jales de Oliveira ${ }^{1}$, Alex Sandro Gomes ${ }^{2}$, \\ Francisco Milton Mendes Neto ${ }^{1}$ \\ ${ }^{1}$ Universidade Federal Rural do Semi-Árido (UFERSA) \\ Mossoró - RN - Brasil \\ ${ }^{2}$ Universidade Federal de Pernambuco (UFPE) \\ Recife - PE - Brasil \\ brunomonteiro@ufersa.edu.br, verto.jales@gmail.com, asg@cin.ufpe.br, \\ miltonmendes@ufersa.edu.br
}

\begin{abstract}
This work presents the design, implementation and evaluation of Youubi, a ubiquitous learning environment distributed under an open source license. Currently, the project offers a client for Android smartphones and tablets. Students and teachers used it for four weeks. The results provide evidence that there was an increase in engagement of apprentices, as well as the emergence of new learning practices among students and teachers who have used it during that period.
\end{abstract}

Resumo. Este trabalho apresenta a concepção, implementação e avaliação do Youubi, um ambiente de aprendizagem ubíqua distribuído sob uma licença open source. Atualmente o projeto disponibiliza um cliente para smartphones e tablets Android, que foi utilizado por estudantes e professores durante quatro semanas. Os resultados proveem indícios de que houve aumento no engajamento dos aprendizes, como também o surgimento de novas práticas entre os estudantes e professores que o utilizaram durante esse período.

\section{Introdução}

A perspectiva de cenários dinâmicos e a cobrança por modernidade impulsionam a adoção, e supervalorização, de ferramentas baseadas nas tecnologias da informação e comunicação (TIC) nas práticas educacionais. Porém sua adoção nas práticas de ensinoaprendizagem ainda se limita aos muros das instituições, sem perceber o contexto dos estudantes e ignorando suas motivações. Além disso, muitas iniciativas com essa preocupação ainda se restringem a pesquisas acadêmicas sem uma efetiva disponibilização e popularização das soluções propostas, na forma de artefatos de software para estudantes e professores.

Diante desses problemas, o presente trabalho baseia-se nos princípios da aprendizagem ubíqua (u-learning) e propõe-se a explorar situações de aprendizado em ambientes formais e informais; de forma lúdica; que utilize recursos tecnológicos de baixo custo; e que se reconheça o cotidiano, os interesses, as motivações e as interações sociais dos estudantes e professores. Para isso, estabeleceu-se como objetivo conceber, desenvolver e avaliar um ambiente de $u$-learning, chamado aqui de Youubi, distribuído sob uma licença de software livre (GPL2); e analisar os impactos no engajamento dos estudantes, as práticas e estratégias de aprendizado adotadas por eles, como também as impressões dos professores quanto ao uso dessa ferramenta. 
Para alcançar esse objetivo, o método de pesquisa foi dividido em duas fases. Primeiramente, por meio de técnicas de design interativo, buscou-se conceber e implementar um sistema de u-learning que potencialize essas situações de aprendizagem. Em seguida, utilizando técnicas quantitativas e qualitativas de coleta e análise de dados, pretendeu-se verificar, entre os estudantes e os professores, a influência dessa ferramenta nos cenários e estratégias de aprendizagem, e sobre as motivações e o consequente engajamento dos envolvidos em suas atividades.

O modelo conceitual do Youubi gira em torno de seis entidades elementares: pessoas, postagens, eventos, desafios, lugares e grupos. Além disso, a comunicação do servidor do Youubi com suas aplicações clientes é feita sobre Web Service, o que facilita o desenvolvimento de aplicações para web, desktop, smartphones, tablets, smart TV e smartwatches. Para o presente trabalho, foi desenvolvida uma aplicação do Youubi para smartphones e tablets Android.

Por fim, para verificar o impacto desse ambiente de u-learning nas práticas dos estudantes e professores, foi realizado um experimento em uma instituição de ensino de nível superior, durante um período de quatro semanas. Após a análise dos dados, verificou-se, com a introdução do Youubi, o surgimento de práticas lúdicas e colaborativas por parte dos estudantes, além de dados e relatos que apontam para um aumento no engajamento em suas rotinas de estudo.

\section{Ambiente para coordenar situações de aprendizagem ubíqua}

O conceito de computação ubíqua (ubiquitous computing) [Weiser, 1991] surge como um modelo computacional que tem o objetivo de atender pró-ativamente às necessidades dos usuários, atuando de forma "invisível" (background) e integrando continuamente tecnologia e ambiente, de modo a auxiliar o usuário em suas tarefas cotidianas. Segundo esse modelo, serviços e recursos estão sempre disponíveis ao usuário, em qualquer lugar e a qualquer tempo, independente de dispositivo [Barbosa, 2007]. De modo mais concreto, Araújo (2003, p. 48) define um conjunto de características que descrevem um sistema ubíquo: a informação pode ser acessada através de múltiplos dispositivos heterogêneos; a aplicação segue o usuário em movimento; os dispositivos interagem entre si; algumas tarefas são executadas de forma autônoma; dispositivos diferentes apresentam visões diferentes da mesma aplicação; o ambiente troca informações com os dispositivos e vice-versa; e a aplicação responde a mudanças no ambiente. Entretanto, algumas dessas características podem ser observadas em dois outros modelos computacionais: computação móvel e computação pervasiva, conforme ilustra a Figura 1.

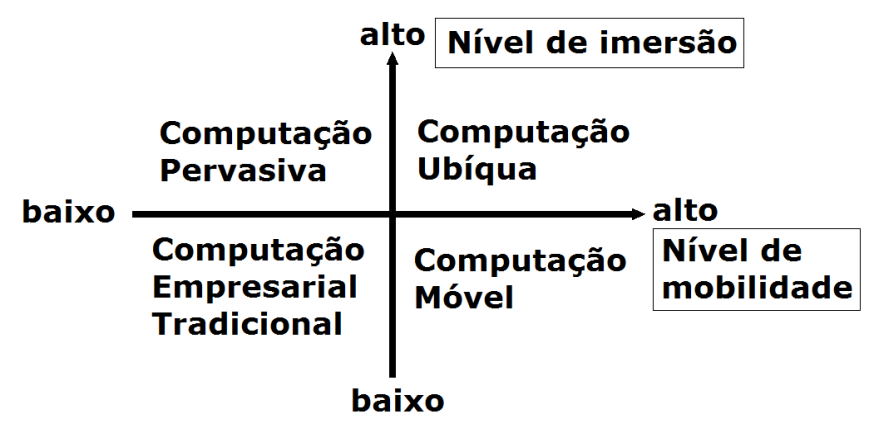

Figura 1 - Relação entre Computação Móvel, Pervasiva e Ubíqua [Lyytinen e Yoo, 2002] 
Em sistemas baseados em computação ubíqua, destaca-se também o recurso de geolocalização, que se refere à determinação da posição geográfica de uma pessoa, lugar ou objeto, definida pelas componentes de latitude e longitude, e obtidas, por exemplo, por sensores de GPS (Global Positioning System), comumente presente em tablets e smartphones. Dessa forma, com a popularização dos dispositivos capazes de obter dados de geolocalização, cresce também o desenvolvimento de aplicações de geotagging, que se refere à adição de metadados que permitem descrever a posição geográfica de mídias digitais, tais como fotografias, vídeos, mensagens, páginas web, entre outras [Holdener, 2011].

No âmbito educacional, com cada vez mais acesso a dispositivos computacionais conectados à Internet, os indivíduos experimentam a possibilidade de produzir e disseminar informações, de modo fácil, rápido e situado, conforme for sua necessidade e vontade. Portanto, tal cenário permite também que a aprendizagem possa ocorrer em qualquer tempo e espaço, dentro ou fora dos muros das instituições, seja a respeito de temas curriculares, ou simplesmente sobre curiosidades e interesses particulares. Em outras palavras, a aprendizagem não precisa ocorrer apenas em sala de aula, mas pode acontecer também: em casa, no trabalho, no pátio das escolas, na biblioteca, em museus, em parques e nas interações cotidianas com os outros. Por exemplo, por meio dos dispositivos móveis, o aprendiz é capaz de interagir com o meio, capturando imagens, sons, informações de localização, vídeos e conectando-se a dispositivos distribuídos no ambiente. A possibilidade de capturar e compartilhar informações em contextos diferentes, motiva a investigação pessoal e o indivíduo cria novas situações de aprendizagem por meio das interações com o ambiente e com seus pares [Galeno, 2010].

Neste sentido, as características inerentes ao modelo de computação ubíqua abrem diversas e relevantes oportunidades quando aplicadas ao contexto educacional. Para essa combinação, de tecnologias baseadas no modelo de computação ubíqua para promover modelos de aprendizagem preparados para lidar com a mobilidade e se adequar aos diferentes contextos do cotidiano dos estudantes, surge o conceito de aprendizagem ubíqua (ubiquitous learning ou u-learning). Assim, de modo geral, o conceito de $u$-learning refere-se ao conjunto de processos de aprendizagem apoiados por tecnologias digitais que possibilitem integrar os aprendizes com o seu contexto de aprendizagem, com seu cotidiano, sua rede social e seu ambiente físico, possibilitando aproximar, no ambiente virtual e presencialmente, pessoas, objetos, lugares, conteúdos, atividades e eventos, de modo a potencializar oportunidades de aprendizagem contínua, contextualizada e significativa [Saccol, Schlemmer e Barbosa, 2011].

\section{Método}

Para contemplar os objetivos deste trabalho, o método de pesquisa concebido foi dividido em duas etapas, fez uso de técnicas do Design Interativo [Preece, Rogers e Sharp, 2005] e segue as orientações da Pesquisa Qualitativa [Flick, 2009], que se complementa com técnicas quantitativas e procedimentos interpretativos, conforme ilustra a Figura 2.

Primeiramente, a Etapa 1 teve como objetivo conceber, implementar e validar o ambiente de u-learning Youubi para que ele pudesse ser utilizado posteriormente na Etapa 2. Na sequência, a Etapa 2 do método teve como objetivo realizar a coleta e análise dos dados necessários para a verificação da hipótese de trabalho "A adoção do 
ambiente de $u$-learning promoveu diferença positiva na motivação e no engajamento dos aprendizes". Esta etapa teve duração de aproximadamente quatro semanas e, durante esse período, os professores e estudantes do Grupo Experimental instalaram o Youubi Android, desenvolvido na Etapa 1, em seus próprios smartphones, e puderam utilizá-lo livremente em qualquer lugar.

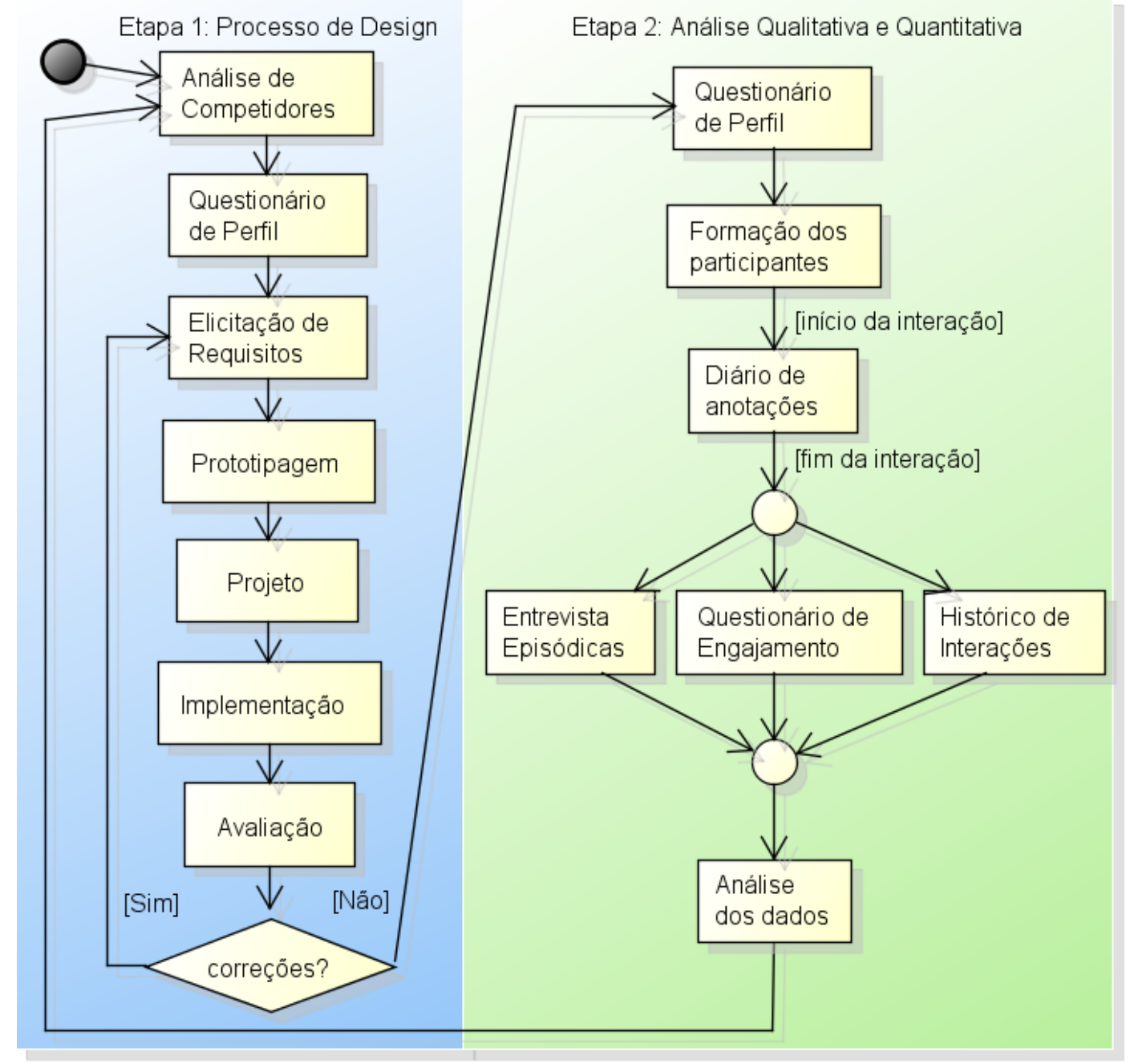

Figura 2 - Método de pesquisa para concepção e avaliação do Youubi

Ao todo, foram mobilizados 132 participantes, da Universidade Federal Rural do Semi-Árido, distribuídos da seguinte forma: para a Etapa 1 foram selecionados 90 estudantes do curso de Ciência e Tecnologia; todos esses foram convidados a preencher o Questionário de Perfil, porém foi selecionado um subgrupo de cinco estudantes para participarem da atividade de avaliação do Youubi, pois se encaixavam nos seguintes pré-requisitos: possuir smartphone compatível com as tecnologias adotadas e possuir serviço de Internet móvel. Conforme Nielsen (1994), essa amostragem de cinco participantes é capaz de identificar aproximadamente $70 \%$ dos problemas de usabilidade mais críticos. Em seguida, para a Etapa 2, foram selecionados 2 professores e 40 estudantes dos cursos de Ciência e Tecnologia e de Biotecnologia. Nessa etapa, os estudantes que utilizaram o Youubi formaram o Grupo Experimental, e os estudantes que não o utilizaram se referem ao Grupo de Controle. 


\section{Resultados da Etapa 1: Concepção do Youubi}

Com base nas informações de revisão bibliográfica e naquelas resultantes das primeiras atividades da Etapa 1 do método de pesquisa (Análise de Competidores e Questionário de Perfil), foram elencados os requisitos funcionais do Youubi. Uma vez que a lista de requisitos tornou-se estável, ela pôde servir de base para a concepção da arquitetura de referência (Figura 3) e, consequentemente, para os artefatos de software "Youubi Server" e "Youubi Android". Entretanto, vale salientar que novos requisitos foram adicionados e outros foram corrigidos após a atividade de Avaliação do Youubi junto aos usuários, no final da Etapa 1 do método. Essa versão avaliada e corrigida foi então utilizada por estudantes e professores para a execução do experimento da Etapa 2.

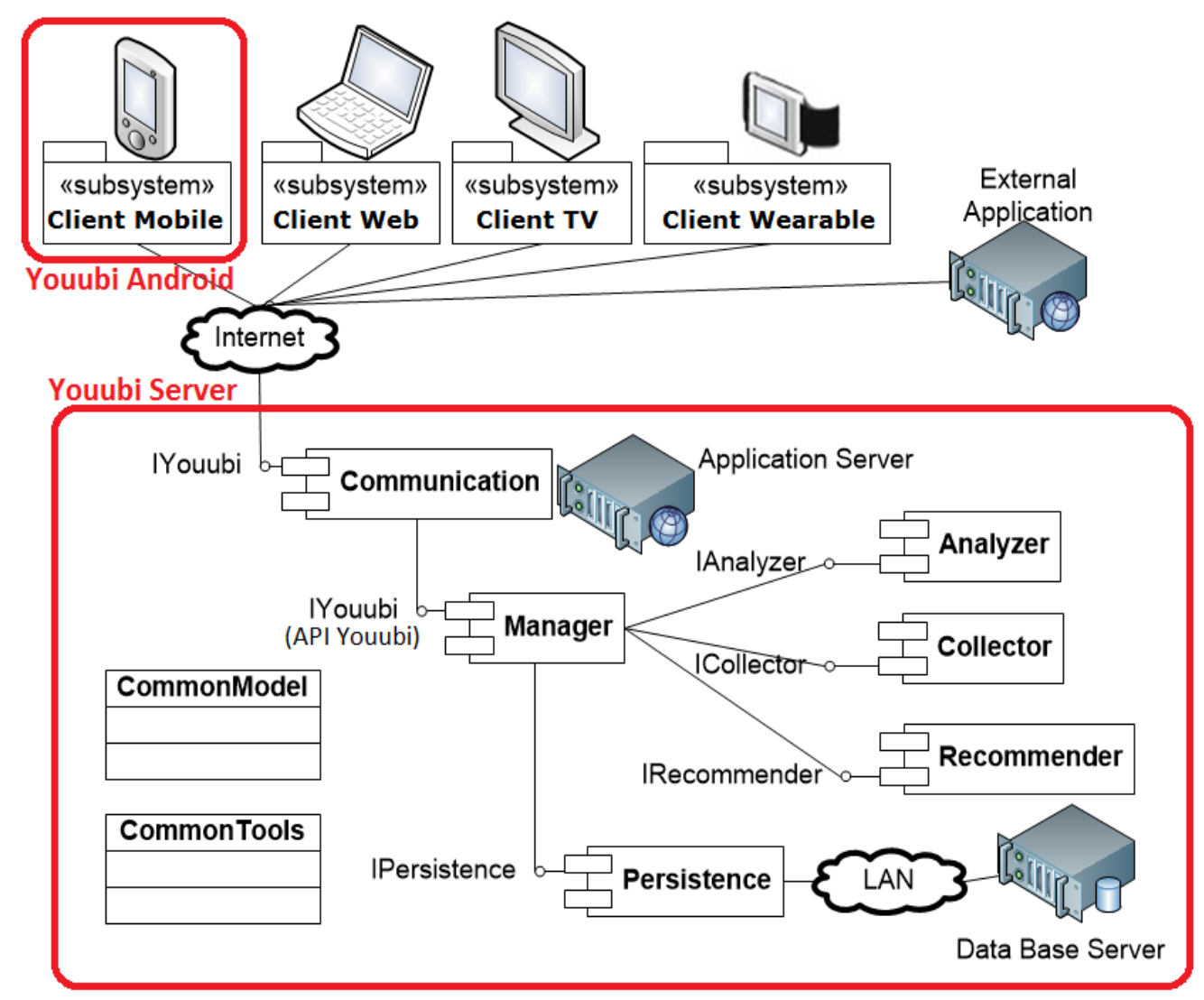

Figura 3 - Representação da arquitetura do Youubi

\subsection{Youubi Server}

O Youubi adota o modelo de referência Cliente-Servidor [Kurose e Ross, 2006]. A arquitetura de referência, depois de idealizada, foi implementada, utilizando a linguagem de programação Java, para dar origem à arquitetura de software, que neste trabalho é chamada de Youubi Server. Seu modelo de dados é composto por dezenas de classes, porém seis delas compõem as entidades elementares (Tabela 1), que derivam os objetos que representam os usuários e os objetos que esses podem criar e manipular. É importante destacar que todas essas entidades possuem atributos de geolocalização, o que permite associá-las a uma posição geográfica real. 
Tabela 1 - Entidades Elementares do Youubi

\begin{tabular}{|c|l|}
\hline Entidade & \multicolumn{1}{c|}{ Descrição } \\
\hline Person & $\begin{array}{l}\text { Representa cada usuário e possui atributos que representam seu contexto estático e dinâmico. } \\
\text { Possui relacionamento com Post, Event, Challenge, Group, Location e também com a própria } \\
\text { Person, para que possa dar suporte a requisitos de rede social. }\end{array}$ \\
\hline Location & $\begin{array}{l}\text { Representa uma localização, que pode ser criada, comentada, avaliada e compartilhada pelos } \\
\text { usuários. É composta por sua coordenada, endereço, nome, descrição e imagem. }\end{array}$ \\
\hline Post & $\begin{array}{l}\text { Representa uma postagem, que pode ser criada, comentada, avaliada e compartilhada pelos } \\
\text { usuários. Pode ser composta por textos, links e arquivos, inclusive imagens. }\end{array}$ \\
\hline Event & $\begin{array}{l}\text { Representa um evento do tempo, que pode ser criado, comentado, avaliado e compartilhado } \\
\text { pelos usuários. Sua adoção se baseia nas estratégias de autorregulação [Souza, 2012]. }\end{array}$ \\
\hline Challenge & $\begin{array}{l}\text { Representa um desafio na forma de um quiz, que pode ser criado, comentado, avaliado e } \\
\text { compartilhado pelos usuários. Possibilita o desenvolvimento de práticas lúdicas embasadas nos } \\
\text { princípios da aprendizagem ativa [Prince, 2009] e em estratégias de gamification [Seixas, } \\
\text { 2014]. }\end{array}$ \\
\hline Group & $\begin{array}{l}\text { Representa um conjunto de pessoas que compartilham entre si eventos, mensagens, postagens e } \\
\text { desafios. Pode ser criado e avaliado pelos usuários. Possibilita práticas baseadas nas teorias da } \\
\text { aprendizagem sócio interacionista [Vigotski, 2007] e cognição situada [Lave; Wenger, 1991]. }\end{array}$ \\
\hline
\end{tabular}

A arquitetura do Youubi também é composta por oito componentes internos do lado do servidor (Tabela 2), e seus serviços podem ser consumidos por aplicações clientes como, por exemplo, para smartphones, tablets, aplicações web, smart TV e smartwatches, ou por outros sistemas, por meio de uma API (Application Programming Interface) de serviços. Essa API provê métodos que devem suportar casos de uso de uma rede social on-line [Benevenuto; Almeida e Silva, 2011], como também serviços específicos para ambientes de u-learning sensíveis ao contexto. Cada um dos componentes internos da arquitetura possui uma atribuição específica e uma interface de serviços bem definida, o que garante propriedades de baixo acoplamento e alta coesão.

Tabela 2 - Componentes internos do Youubi Server

\begin{tabular}{|c|l|}
\hline Componente & \multicolumn{1}{c|}{ Descrição } \\
\hline Communication & $\begin{array}{l}\text { Representa a camada de comunicação, pois permite que as aplicações clientes utilizem a } \\
\text { API Youubi para requisitar os serviços do Youbi Server. Foi implementada sobre Web } \\
\text { Service com o framework RESTEasy, o que permite receber e responder as requisições } \\
\text { com o protocolo padrão HTTP (Hypertext Transfer Protocol). }\end{array}$ \\
\hline Manager & $\begin{array}{l}\text { Processa as requisições passadas por Communication. É responsável por gerenciar as } \\
\text { regras de negócio, e distribuir demandas aos outros componentes. Também atualiza } \\
\text { indicadores que permitem identificar padrões de comportamento dos usuários. Essa } \\
\text { estratégia reduz o processamento em lote e garante o acesso a esses dados em tempo real. }\end{array}$ \\
\hline Collector & $\begin{array}{l}\text { É responsável por coletar dados sobre outros sistemas que disponibilizam uma API de } \\
\text { acesso. Para a versão atual, utiliza-se a API do Google para, com base nas coordenadas de } \\
\text { latitude e longitude, obter detalhes de um determinado local. }\end{array}$ \\
\hline Analyzer & $\begin{array}{l}\text { É responsável por analisar os dados armazenados no banco de dados a fim de identificar } \\
\text { novas informações que possam enriquecer o perfil dos usuários. }\end{array}$ \\
\hline Recommender & $\begin{array}{l}\text { É responsável por gerar uma lista de objetos recomendados para cada entidade elementar } \\
\text { do Youubi (Person, Post, Event, Challenge, Location e Group). }\end{array}$ \\
\hline Commontence & $\begin{array}{l}\text { É responsável pela persistência dos dados. Utiliza o padrão JPA (Java Persistence API) } \\
\text { sobre o framework EclipseLink, no SGBD PostgreSQL. }\end{array}$ \\
\hline CommonModel & $\begin{array}{l}\text { É composto por diversos métodos utilitários como, por exemplo, algoritmos de conversão. } \\
\text { Dessa forma, evita regras de negócio no componente CommonModel. } \\
\text { as entidades elementares (Person, Post, Event, Challenge, Location e Group). Suas } \\
\text { classes e seus atributos utilizam as annotations do padrão JPA. }\end{array}$ \\
\hline
\end{tabular}


CBIE-LACLO 2015

Anais do XXVI Simpósio Brasileiro de Informática na Educação (SBIE 2015)

\subsection{Youubi Android}

Uma vez criado o Youubi Server, foi iniciada a implementação de um aplicativo cliente para smartphones e tablets. Além ser um dos objetivos específicos, este cliente também permitiu validar os serviços oferecidos pelo Youubi Server. Para a implementação desse cliente, adotou-se o sistema Android, por isso é chamado aqui de Youubi Android (Figura 4 e Figura 5). Essa plataforma foi escolhida com base em dados de market share da Kantar (2014), que apontam que, no Brasil, em 2013, o Android era o sistema presente em $87 \%$ dos smartphones. Além disso, adotou-se a versão Ice Cream Sandwich (API 15) do Android, compatível com 94\% dos aparelhos Android [Google, 2015].

De modo a ampliar o alcance do Youubi Android, a aplicação adota recursos de internacionalização, o que permite alterar a interface gráfica para o idioma inglês. Outro recurso adotado foi o Google Cloud Messaging (GCM), que permite a comunicação assíncrona entre o servidor e o dispositivo, o que aumenta a eficiência do sistema, pois evita processos síncronos e possibilita que o usuário seja alertado imediatamente, por exemplo, diante do recebimento de novas mensagens de chat, solicitações de amizade, comentários ou avaliações dos seus conteúdos, e recomendações de novos conteúdos.

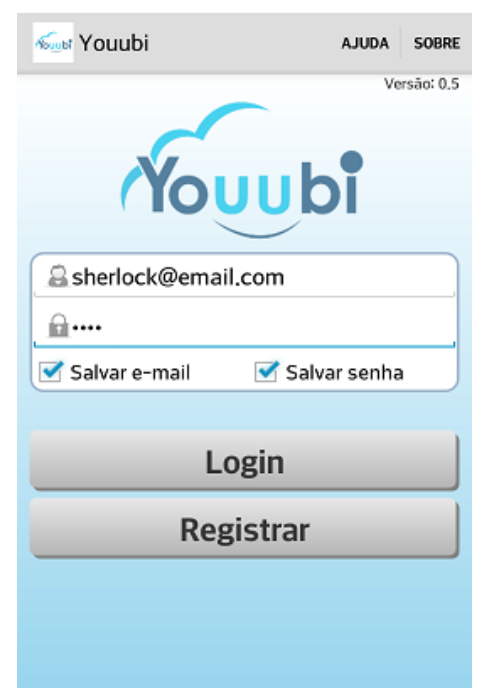

a) Tela de login

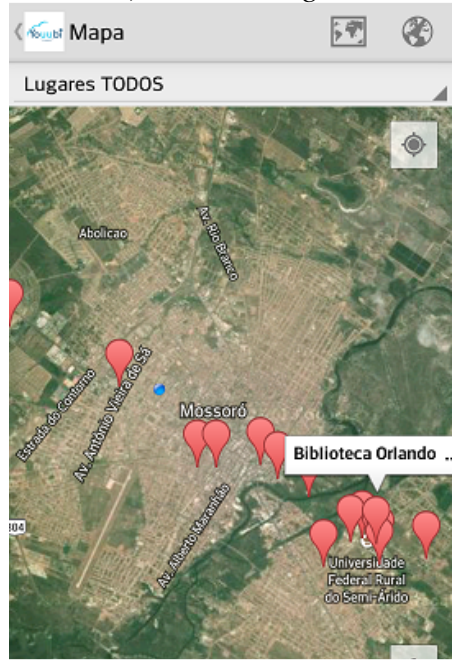

d) Mapa

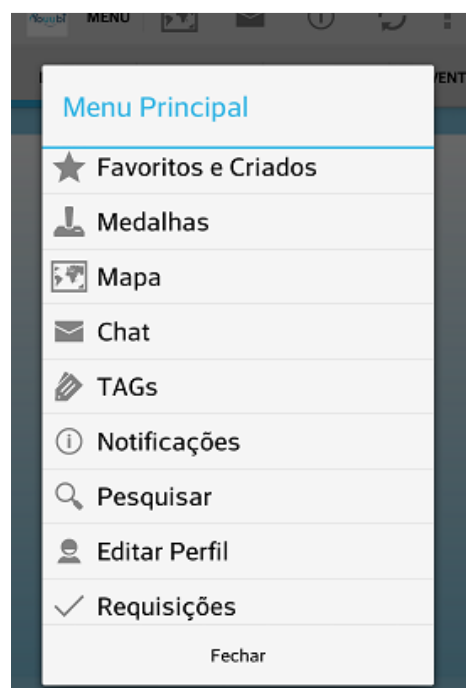

b) Menu principal

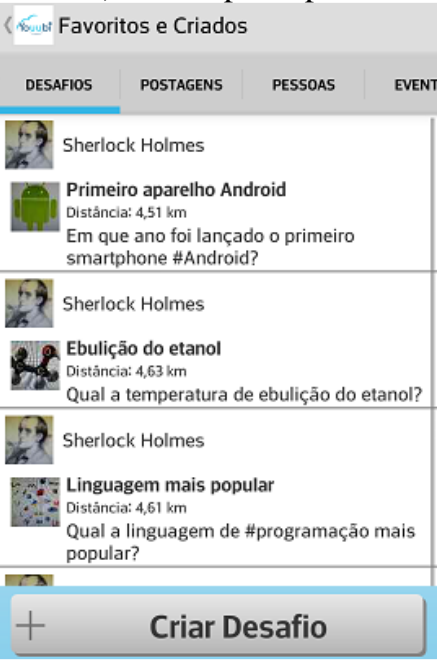

e) Elementos criados e favoritos

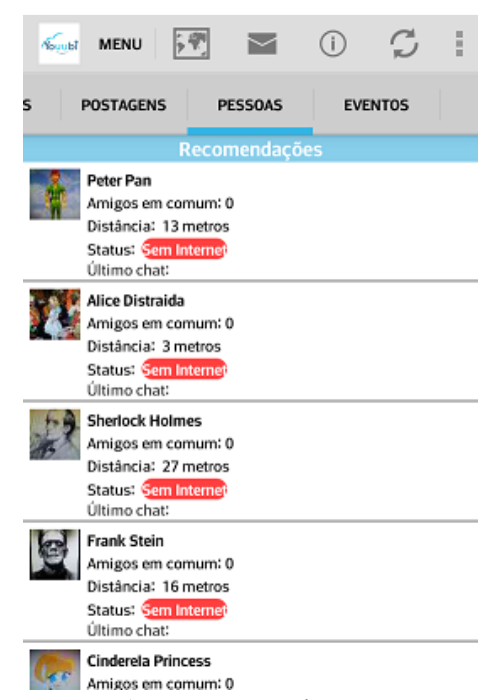

c) Recomendações

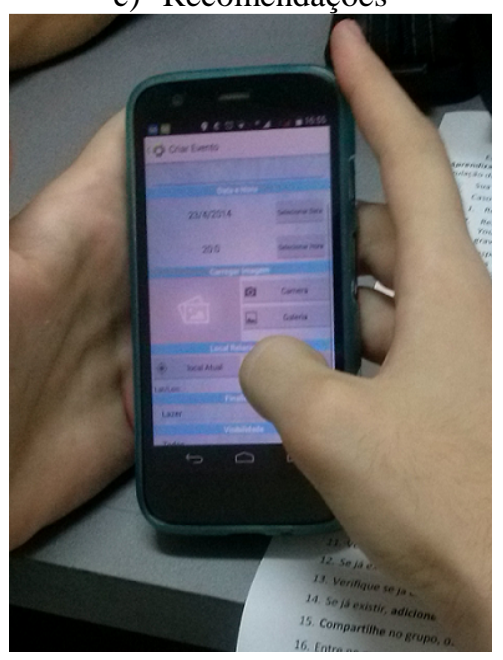

f) Participante criando evento

Figura 4 - Telas do Youubi Android 


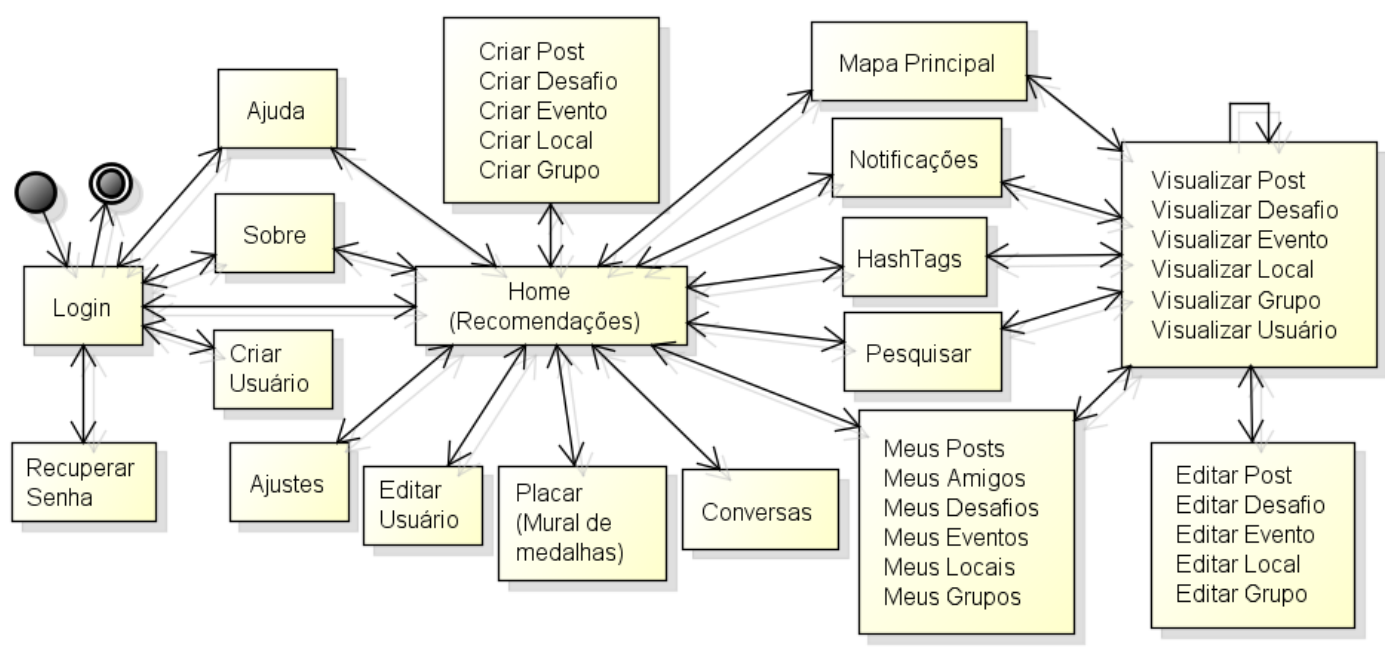

Figura 5 - Versão simplificada do diagrama de navegação de telas

\section{Resultados da Etapa 2: Avaliação da efetividade do Youubi}

Esta seção tem como objetivo apresentar os resultados obtidos com as atividades realizadas na Etapa 2 do método de pesquisa (Figura 2), que faz uso dos artefatos de software produzidos na Etapa 1 (Youubi Server e Youubi Android). Primeiramente, foi realizada a análise quantitativa sobre os dados dos questionários, entre grupo de Controle e grupo Experimental, e histórico de interações no Youubi com os participantes do grupo Experimental e professores. Os primeiros resultados dão indícios de que houve um aumento nas variáveis ${ }^{1}$ de motivação e engajamento entre os estudantes do grupo Experimental, conforme Figura 6a. Com relação à variável "realizações", apesar do Youubi ter sido utilizado após as avaliações da Unidade 1, as notas do grupo Experimental se mantiveram acima do grupo de Controle (Figura 6b).

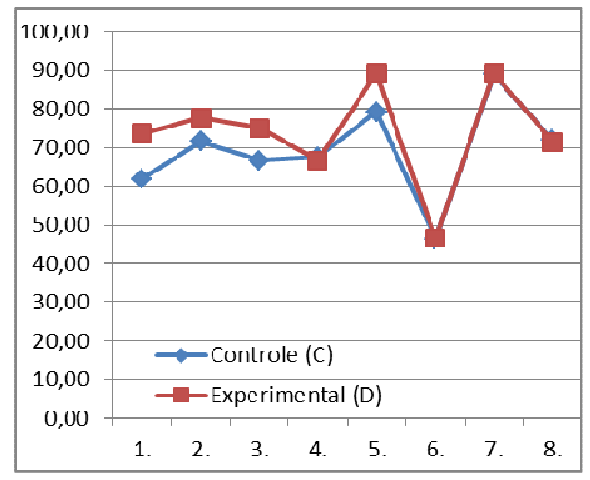

a) Dados do questionário de engajamento

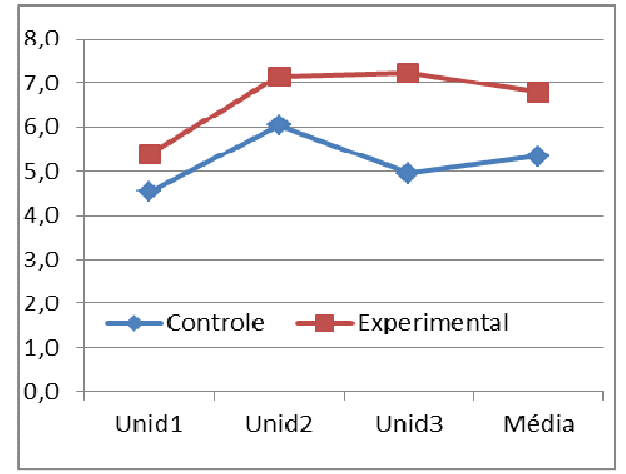

b) Evolução das notas dos alunos na disciplina

Figura 6 - Grupos de Controle e Experimental nas turmas de Ciência e Tecnologia.

Em seguida, essas primeiras verificações foram complementadas com a análise dos relatos dos participantes, coletadas pelos questionários, diários de anotação e entrevistas. Essa análise qualitativa foi útil para sugerir as práticas, funcionalidades e cenários que podem ter influenciado no aumento do engajamento dos estudantes.

\footnotetext{
1 Variáveis de motivação e engajamento conforme o modelo proposto por Greene et al. (2004): 1. Tarefas Motivadoras; 2. Apoio à Autonomia; 3. Avaliação do Nível de Domínio; 4. Auto Eficácia; 5. Metas de Domínio; 6. Metas de Desempenho; 7. Instrumentalidade Percebida; 8. Uso de Estratégias; 9. Realizações.
} 
Foram ainda observadas as características que mais chamaram a atenção e as perspectivas de adoção desse tipo de ferramenta pelos professores. Um resumo dos relatos dos participantes (estudantes e professores) pode ser observado na Tabela 3.

Tabela 3 - Resumo dos relatos dos participantes.

\begin{tabular}{|c|c|}
\hline Tópico & Relatos dos estudantes e professores \\
\hline $\begin{array}{l}\text { Importância do } \\
\text { lúdico }\end{array}$ & $\begin{array}{l}\text { "Assim que a gente instalou estava todo mundo comentando, rindo, tirando foto, participando } \\
\text { dos desafios, foi bem legal. Eu continuaria utilizando o aplicativo". }\end{array}$ \\
\hline $\begin{array}{l}\text { Colaboração } \\
\text { nos desafios e } \\
\text { nos grupos }\end{array}$ & $\begin{array}{l}\text { "Eu estava em casa, e tinha uma pergunta, e eu envolvi todo mundo que estava lá ao meu } \\
\text { redor para me ajudar a responder. Fui buscar conhecimento através de outras pessoas para } \\
\text { responder certo"; "Eu criei um grupo. Acho que é legal juntar a galera da turma para falar do } \\
\text { assunto da aula, por exemplo". }\end{array}$ \\
\hline $\begin{array}{l}\text { Competitividade } \\
\text { como motivação }\end{array}$ & $\begin{array}{l}\text { "Eu senti um clima de competição, mas no bom sentido. Eu estava até conversando com uma } \\
\text { amiga que estava participando. Ela dizia, entra aí no meu perfil e vê quantas medalhas eu } \\
\text { tenho. Vamos ver quem está respondendo e participando". }\end{array}$ \\
\hline $\begin{array}{l}\text { Incentivo à } \\
\text { Pesquisa }\end{array}$ & $\begin{array}{l}\text { "Pelo APP ter aquela parte de desafio, a gente se torna mais motivado a buscar coisas na } \\
\text { Internet, a resposta certa, agente vai pesquisando, e é uma forma de estudo, né?" }\end{array}$ \\
\hline $\begin{array}{l}\text { Autoria de } \\
\text { conteúdos }\end{array}$ & $\begin{array}{l}\text { "Criei locais e um grupo da disciplina. Criei local da aula que eu estava assistindo e criei esse } \\
\text { local que a gente está agora. Tirei a 'fotinha' e tudo. Achei interessante. É legal colocar } \\
\text { conteúdos relacionados aquele local. Poder relacionar postagem da aula e 'linkar' direto com } \\
\text { o local da aula, usar hashtag". }\end{array}$ \\
\hline $\begin{array}{l}\text { Reconheciment } \\
\text { o como } \\
\text { motivação }\end{array}$ & $\begin{array}{l}\text { "Foi bom, eu vi muita gente curtindo as coisas que criei. Me senti como se tivesse fazendo } \\
\text { algo útil. Os desafios que criei muita gente respondeu. Quanto mais eu criava mais vontade } \\
\text { dava de criar mais coisas". }\end{array}$ \\
\hline $\begin{array}{l}\text { Importância da } \\
\text { geolocalização }\end{array}$ & $\begin{array}{l}\text { "Eu achei bem legal saber a distância, saber as coisas que estão perto de você e a distância } \\
\text { Saber o que está acontecendo na biblioteca, os eventos da universidade. Você fica curioso } \\
\text { por saber o que está perto". }\end{array}$ \\
\hline $\begin{array}{l}\text { Importância das } \\
\text { recomendações }\end{array}$ & $\begin{array}{l}\text { "É muito interessante, entrar e não precisar procurar. As coisas já estavam lá para você ver } \\
\text { Postagens das pessoas que você conhece ou que estão no mesmo local"; "[as recomendações] } \\
\text { influenciam de um modo positivo, porque indicam coisas que eu não sabia, inclusive } \\
\text { relacionadas ao local. Por exemplo, ele me indicou um artigo que eu não conhecia, e que } \\
\text { estava relacionado com a área que eu quero, e fica mais fácil para me interessar pelo assunto" }\end{array}$ \\
\hline $\begin{array}{c}\text { Auxiliar nas } \\
\text { práticas do } \\
\text { professor }\end{array}$ & $\begin{array}{l}\text { "Eu acho que é mais prático trabalhar com um aplicativo que funcione em qualquer lugar. No } \\
\text { celular é mais prático do que no computador. Eu posso postar eventos, postagens em } \\
\text { qualquer lugar, para mim é bom"; "Achei muito bom, já que o [sistema da universidade] não } \\
\text { permite essa habilidade, pois é apenas professor criando conteúdo pros alunos. Com o aluno } \\
\text { criando, eles agora podem falar. Por exemplo, tinha uma questão que a [aluna] que tirou a } \\
\text { dúvida de outro menino. Tem horas que eu não posso responder e eles podem responder. } \\
\text { Então responde! Isso é mais prático pra mim, e para eles" }\end{array}$ \\
\hline
\end{tabular}

\section{Conclusão}

As contribuições deste trabalho, no âmbito da Computação, se referem à concepção de uma arquitetura de referência, cujo modelo de dados, requisitos, entidades elementares e componentes podem servir de base para outros projetos de u-learning. Além disso, de modo a contribuir com a comunidade de forma prática e incentivar a popularização de projetos dessa natureza, os artefatos de software tanto do Youubi Server quanto do Youubi Android estão em fase de registro para serem distribuídos sob uma licença open source, o que permite que os resultados alcançados possam continuar sendo aprimorados.

Quanto às contribuições no âmbito da Educação, verificou-se uma percepção do Youubi como uma ferramenta aliada às práticas dos professores, pois amplia a interação professor-estudante e permite um acompanhamento mais detalhado sobre o aluno, não só quantitativo, mas das atividades e assuntos de interesse. Além disso, após confrontar 
os grupos de controle e experimental, verificou-se uma variação positiva das variáveis que indicam o engajamento dos estudantes, como também de suas notas médias. Essas verificações, com base na análise quantitativa, mostraram indícios que se aproximam da hipótese de que "a adoção do ambiente de u-learning promoveu diferença positiva na motivação e no engajamento dos aprendizes". Para complementar esses resultados, foram também analisados os discursos dos participantes com base na análise qualitativa, de modo a verificar o surgimento de novas práticas, e compreender a subjetividade das suas expectativas e motivações. Por fim, como já informado, o Youubi é distribuído sob uma licença open source, o que reduz os custos e facilita sua implantação nas instituições.

\section{Referências}

Araújo, R. B. (2003). Computação ubíqua: Princípios, tecnologias e desafios. XXI Simpósio Brasileiro de Redes de Computadores (SBRC), Natal, p.11-13.

Barbosa, D. N. F. (2007). Um Modelo de Educação Ubíqua Orientado à Consciência do Contexto do Aprendiz. Tese de Doutorado, Unisinos.

Benevenuto, F.; Almeida, J. M.; Silva, A. S. (2011). Explorando redes sociais online. Minicursos do Simpósio Brasileiro de Redes de Computadores (SBRC), Campo Grande.

Flick, U. (2009). Desenho da pesquisa qualitativa: Coleção Pesquisa qualitativa. Bookman.

Galeno, A. S. (2010) Concepção de módulo para dispositivos móveis de gestão da aprendizagem pessoal integrado ao Amadeus LMS. Dissertação de mestrado. UFPE, Recife.

Google. (2015). Android Developer: Dashboards. Disponível em: <http://developer.android.com/about/dashboards> Acesso em: 28 mai. 2015.

Greene, B. A. et al. (2004). Predicting high school students' cognitive engagement and achievement. Contemporary educational psychology, v. 29, n. 4, p. 462-482.

Holdener, A. T. (2011). HTML5 Geolocation. O'Reilly Media, Inc..

Kantar World Panel. (2014). Smartphone OS market share. Kantar Group. Disponível em: <www.kantarworldpanel.com/smartphone-os-market-share>. Acesso em: 28 mar. 2014.

Kurose, J.; Ross, K. (2006). Redes de Computadores e Internet. São Paulo: Person.

Lave, J.; Wenger, E. (1991). Situated learning: Legitimate peripheral participation. Cambridge University Press.

Lyytinen, K.; Yoo, Y. (2002). Ubiquitous computing. Communications of ACM, v.45, n.12, p.63.

Nielsen, J. (1994). Usability Engineering. Elsevier.

Preece, J.; Rogers, Y.; Sharp, H. (2005). Design de interação. Bookman.

Prince, M. (2004) Does active learning work? A review of the research. Journal of engineering education, v. 93, n. 3, p. 223-231.

Saccol, A.; Schlemmer, E.; Barbosa, J. (2011). M-Learning e U-Learning: Novas Perspectivas da Aprendizagem Móvel e Ubíqua. Pearson. São Paulo.

Seixas, L. R. (2014) A Efetividade de Mecânicas de Gamificação sobre o Engajamento de Alunos do Ensino Fundamental. Dissertação de Mestrado. UFPE, Recife.

Souza, F. V. C. (2012) Estratégias de autorregulação de aprendizagem mediado por ferramentas de schedulling em uma plataforma social educacional. Tese de Doutorado. UFPE, Recife.

Vigotski, L. S. (2007). A formação social da mente. São Paulo: Martins Fontes.

Weiser, M. (1991) The computer for the 21st century. Scientific American, v.265, n.3, p.94-104. 